\title{
Diagnosis of Babesia gibsoni in dogs by Molecular and Microscopy Techniques
}

\author{
S. S. Shinde*, B. N. Ambore, P. D. Pawar, S. B. Swami, G. D. Wankhede and C. S. Mote \\ Department of Veterinary Clinical Medicine, Ethics \& Jurisprudence, Krantisinh Nana Patil \\ College of Veterinary Science, MAFSU, Shirwal, Dist. Satara (MS), India \\ *Corresponding author
}

\section{A B S T R A C T}

Keywords

Babesia gibsoni, Peripheral blood smear examination, PCR

Article Info

Accepted:

17 January 2021

Available Online:

10 February 2021
Canine babesiosis is an important worldwide, emerging tick-borne haemoprotozoan disease caused by variety of parasites of the genus Babesia typically by Babesia canis vogeli or Babesia gibsoni in India. Present study estimated the incidence of Babesia gibsoni in dog population in and around Shirwal region of Satara district, Maharashtra State. Incidence was estimated on the basis of screening by microscopic examination and PCR. The most common clinical signs exhibited were fever, lethargy, inappetence and pale/congested mucus membranes. A total of 31 blood samples from dogs clinically showing signs of Babesia gibsoni infection were collected from different breeds, genders and age group. Of 31 samples screened, $30(96.77 \%)$ and $31(100 \%)$ were positive by microscopy and PCR, respectively. Higher incidence was seen in above one year age group (77.42\%) of dogs, breed wise it was more in Labrador Retrievers breed $(35.48 \%)$ and male dogs (61.29\%) were mostly affected.

\section{Introduction}

The dog-human bonding has significant emotional and psychological impact on human lives. Dogs are susceptible to many non-infectious and infectious diseases. In India, prevalence of canine vector borne diseases has been increased over a past few years. But very little information is available regarding many aspects of Canine Babesiosis, an important worldwide, emerging tick-borne haemoprotozoan disease caused by variety of parasites of the genus Babesia typically by Babesia canis vogeli or Babesia gibsoni in India (Jain et al., 2017).Over hundreds of
Babesia spp. reported in the vertebrate hostsand it is thought that potentially all vertebrates, including human (El-Bahnasawy et al., 2011), can be infected with Babesia, largely depending on their suitability as hosts for tick vectors (Schnittger et al., 2012).

Canine Babesiosis is endemic in India because of the presence of tick vectors around the year and stray dog population (Abd Rani et al., 2011). Also the Indian climate favors survival and development of tick vectors making it easy to increase the incidence of tick borne parasitic diseases. Babesia gibsoni is mainly transmitted by brown dog tick, 
Rhipicephalus sanguineus (Solano-Gallegoa and Baneth, 2011 and Jain et al., 2017). It may be sporadically occurs in the world because it can be transmitted by transfusion of Babesia gibsoni-infected blood and dog bites (Koster et al., 2015; Miyama et al., 2005 and Matsuu et al., 2004).

The babesia can be seen as non-pigment forming pear or signet-ring shaped organisms in mammalian erythrocytes, belonging to the order Piroplasmida in the phylum Apicomplexa (Schnittger et al., 2012 and Koster et al., 2015).

Canine Babesia species morphologically categorized into large form $(4-5 \mu \mathrm{m})$ i.e. Babesia canis vogeli occurring as a single or paired within cell and small form $(1-2.5 \mu \mathrm{m})$ i.e. Babesia gibsoni occurring as a single round or oval forms within cell. In India, Babesia canis is more prevalent in southern region while Babesiagibsoni is more prevalent in northern region (Karunakaran et al., 2011).

The disease onset is often acute with affected dogs showing symptoms like fever and lethargy and thereafter may display clinical signs like anorexia, liver or kidney dysfunction, haemostatic abnormalities including coagulation, electrolyte imbalances with regenerative anaemia (Koster et al., 2015 and Baneth, 2018).

The babesiosis is screened traditionally by demonstration of ring shaped, oval, parachute and comma-like parasites within the infected RBCs in Wright-Giemsa stained thin blood smears prepared from the ear margin and was observed under oil immersion (100x) (Matijatko et al., 2007 and Yogeshpriya et al., 2018).

The diagnosis of babesiosis was confirmed by Polymerase Chain Reaction (PCR) because it is an effective tool to identify the subspecies as well as it provides a definitive diagnosis when conventional methods give false negative result (Mahalingaiah et al., 2017).

So, it is crucial to use suitable sensitive as well as specific PCR assays along with microscopy for accurate diagnosis of $B$. gibsoni.

\section{Materials and Methods}

\section{Selection of animals}

Dog presented in the TVCC showing the signs of eitherfever/enlarged lymph nodes/anaemia/lethargy were screened for Canine Babesiosis.

\section{Microscopic examination}

\section{Collection of samples}

Thin blood smear was made by placing a drop of blood taken from tip of the ear of suspected dogs, on a clean glass slide (Figure 1). Smear was prepared, air dried and fixed in methanol.

\section{Staining of blood smears}

Methanol fixed smears were stained using Giemsa stain for 20 minutes and stained blood smears were examined under light microscope by using the oil immersion objective lense (100x). Obtained results were compared with PCR assay result.

\section{Polymerase Chain Reaction (PCR)}

\section{Protocol for Genomic DNA Extraction}

As per the protocol described in HiMedia'sHiPurA ${ }^{\circledR}$ Blood Genomic DNA Miniprep Purification Kit, genomic DNA was isolated from whole blood and stored at $-20^{\circ} \mathrm{C}$ until the further use. 
DNA Amplification and detection of $B$. gibsoni targeting mitochondrial cox3 gene

Extracted DNA was used as a template to amplify the fragment of the B. gibsoni cox3 gene using the reaction mixture given in table 1. The sequences of primer pair $(\mathrm{BgX} 3 \mathrm{~F}$ and $\mathrm{BgX} 3 \mathrm{R}$ ) are provided in table 2 and PCR conditions used are given in table 3.

\section{Results and Discussion}

The cases from January 2020 to November 2020 presented in the Teaching Veterinary Clinical Complex of KNP College of Veterinary Science, Shirwal and Private Pet Clinics in Pune were evaluated.

The total number of cases screened was 97, which showed signs of either fever/ enlarged lymph nodes/ anaemia/ lethargy. Out of 97 screened cases, 31 cases were positive for Babesia gibsoni accounting $31.95 \%$ incidence. Breed-wise incidence was found highest in 11 Labrador (35.48 \%) followed by 4 Non-descript (12.90\%), 3 each in German Shepherd and Golden Retriever (9.67\%), 2 each in Carvan, Doberman, Pitbull and Spitz (6.45\%) and Rottweiler and Pug affected were 1 each $(3.22 \%)$. The incidence in male dogs was higher than in female dogs. Out of 31 dogs affected with Babesia gibsoni 19 $(61.29 \%)$ were male and $12(38.71 \%)$ were female. Age-wise incidence was found highest in dogs above one year age group i.e. $24(77.42 \%)$ than age group below one year 7 $(22.58 \%)$ were positive.

Table.1 Reaction mixture used to amplify the fragment of the B. gibsoni cox3 gene

\begin{tabular}{|c|c|c|}
\hline Sr. No. & Reagents & Volume \\
\hline $\mathbf{1}$ & Master Mix (Takara GT PCR mix) & $12.5 \mu \mathrm{l}$ \\
\hline $\mathbf{2}$ & Forward Primer & $1 \mu \mathrm{l}$ \\
\hline $\mathbf{3}$ & Reverse Primer & $1 \mu \mathrm{l}$ \\
\hline $\mathbf{4}$ & DNA & $4 \mu \mathrm{l}$ \\
\hline $\mathbf{5}$ & Nuclease Free Water & $6.5 \mu \mathrm{l}$ \\
\hline & TOTAL VOLUME & $25 \mu \mathrm{l}$ \\
\hline
\end{tabular}

Table.2 Sequences of primers used in this study

\begin{tabular}{|c|c|c|c|c|}
\hline Name & Sequence & Gene & $\mathbf{T}_{\mathbf{M}}$ & Product Size \\
\hline BgX3F & CAAAATGCCAATATGTACCTAAAC & & & \\
\hline BgX3R & TGTTAATCACAGTTGGTTTACAAC & $\cos 3$ & $56^{\circ} \mathrm{C}$ & $164 \mathrm{bp}$ \\
\hline
\end{tabular}

Table.3 PCR Conditions for Babesia gibsoni DNA Amplification

\begin{tabular}{|c|c|c|c|c|}
\hline \multirow{6}{*}{$\begin{array}{l}\text { Amplification of } \\
\text { 164bp fragment of } \\
\text { Bg cox3 gene of } \\
\text { Babesia gibsoni } \\
\text { (Betgiriet al. 2019) }\end{array}$} & PCR Programme & $\begin{array}{c}\text { TEMPERATURE } \\
\left({ }^{\circ} \mathrm{C}\right)\end{array}$ & TIME & CYCLES \\
\hline & Initial Denaturation & $98^{\circ} \mathrm{C}$ & $1 \mathrm{sec}$ & \multirow{5}{*}{38 Cycles } \\
\hline & Denaturation & $98^{\circ} \mathrm{C}$ & $10 \mathrm{sec}$ & \\
\hline & Annealing & $56^{\circ} \mathrm{C}$ & $30 \mathrm{sec}$ & \\
\hline & Extension & $72^{\circ} \mathrm{C}$ & $30 \mathrm{sec}$ & \\
\hline & Final Extension & $72^{\circ} \mathrm{C}$ & $1 \mathrm{~min}$ & \\
\hline
\end{tabular}


Table.4 Screening of dogs forBabesia gibsoni by peripheral blood smear examination and PCR $(n=31)$

\begin{tabular}{|c|c|c|c|}
\hline Diagnostic Test & $\begin{array}{c}\text { Samples } \\
\text { Screened }\end{array}$ & \multicolumn{2}{|c|}{ Positives } \\
\cline { 3 - 4 } & Number of samples & Per cent \\
\hline $\begin{array}{c}\text { Microscopy } \\
\text { (Blood Smear) }\end{array}$ & 31 & 30 & 96.77 \\
\hline PCR & 31 & 31 & 100 \\
\hline
\end{tabular}

Fig.1 Blood smear preparation in dog

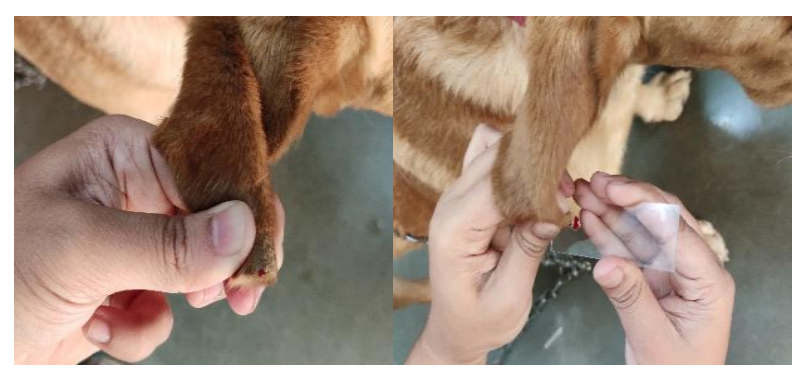

Fig.2 Thin peripheral blood smear of dog showing pleomorphic intra-erythrocytic piroplasms of Babesia gibsoni
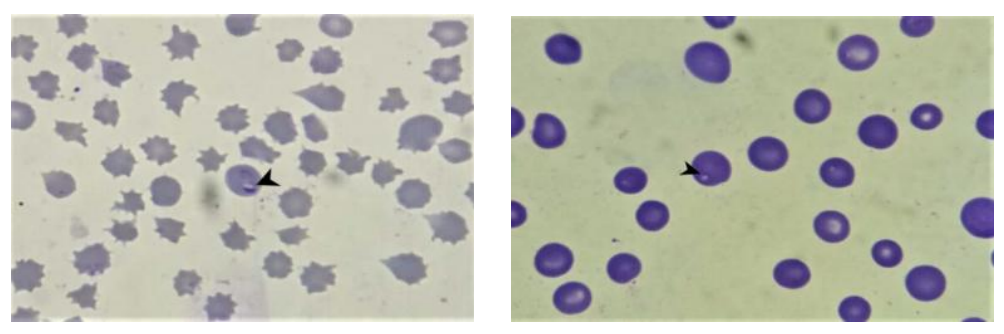

Fig.3 PCR amplification of B. gibsoni cytochrome C oxidase III (cox3) gene with BgX3 primers before treatment: Lane P - Positive control; Lane L - 100 bp ladder; Lane N - Negative control; Lane T11-T15 : samples in group I and lane T21-T25 : samples in group II positive for $B$. gibsoni DNA by cox3 PCR

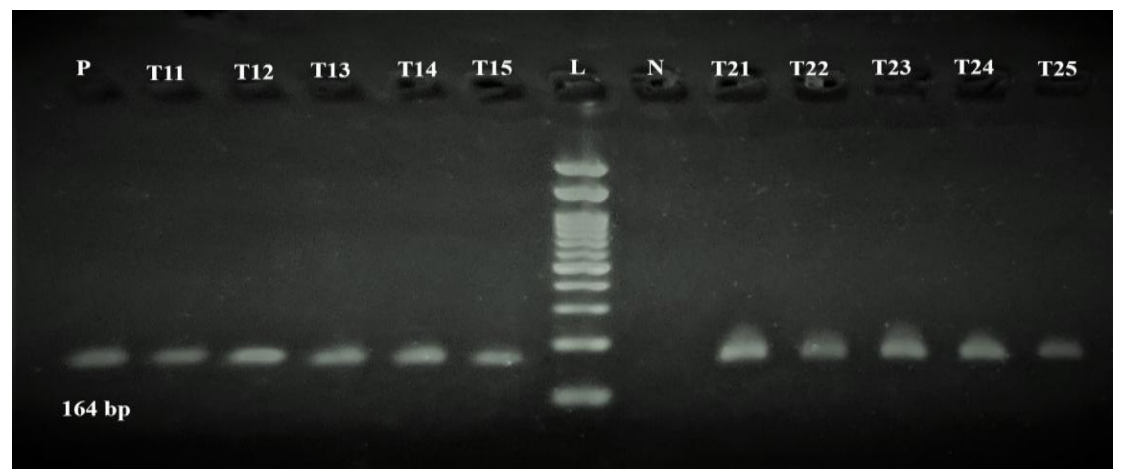




\section{Peripheral blood smear examination}

Microscopic examination of thin Giemsa stained blood smears revealed 30 dogs (96.77 $\%$ ) out of 31 positive for intra-erthrocytic small piroplasms of Babesia gibsoni. Pleomorphic piroplasms, either oval or ring shaped with unipolar or bipolar chromatin condensation at periphery were observed in thin blood smears (Figure 2).

Concurrent infection with other haemoprotozoans were found during peripheral blood smear examination. Mixed infection with B. gibsoni and E. canis was found in one dog.

Detection of haemoprotozoans by microscopic examination of peripheral blood smear is widely used and it is rapid as well as cost effective. Based on peripheral blood smear examination, several epidemiological studies have been conducted (Mahalingah et al., 2017; Das et al., 2015; Laha et al., 2013 and Bhattacharjee and Sarmah, 2013). Although, it is the most accessible and simplest diagnostic test under field conditions and is considered to be a sensitive diagnostic tool during acute clinical cases (Abd-rani et al., 2011). But it is time consuming and it requires technical expertise as parasites can be missed with significantly low parasitaemia and multiple infections in the same host may get undiagnosed as well as chronic or subclinical infections are more common in $B$. Gibsoni (Conrad et al., 1991) which are difficult to diagnose by microscopy alone.

\section{Polymerase chain reaction}

Polymerase Chain Reaction (PCR) targeting mitochondrial cytochrome oxidase subunit III (cox3) detected Babesia gibsoni DNA in 31 blood samples. Out of 31, 30 samples were diagnosed positive for Babesia gibsoni by blood smear examination before treatment. The comparison between peripheral blood smear and PCR examination are depicted in table 4.

The Babesia gibsoni species specific PCR with primer pair $\mathrm{BgX} 3 \mathrm{~F}$ and $\mathrm{BgX} 3 \mathrm{R}$ yielded a specific PCR product of 164 bp from 31 samples. No bands observed with negative control (Betgiri et al., 2018) (Figure 3).

On the basis of the clinical findings in the present study, microscopy could detect 96.77 per cent of Babesia gibsoni positive cases against 100 per cent detection by PCR. Similarly, higher detection of Babesia gibsoni by PCR in comparison to microscopy was also observed by several scientists (Betgiri et al., 2018; Kalaivanan et al., 2018; Jain et al., 2017; Singh et al., 2014 and Laha et al., 2013).

Only one dog had showed false negative result by microscopy which might be due to parasitaemia beyond the level of microscopic detection during very early or carrier stage (Laha et al., 2013). Therefore, use of multiple diagnostic tests is necessary for confirmatory detection canine babesiosis caused by $B$. gibsoni in dogs.

\section{References}

Abd Rani P. A., P. J. Irwin, G. T. Coleman, M. Gatne and Traub, R. J. (2011) A survey of canine tick-borne diseases in India.Parasit Vectors, 141(4): 1-8.

Baneth G. (2018) Antiprotozoal Treatment Of Canine Babesiosis. Vet. Parasitol., 254: 58-63.

Betgiri A. A., S. N. Jadhav, M. Pawde, A. Shukla, C. Mote, P. D. Pawar, D. Shanmugam and Kundu, K. (2019) Mitochondrial cytochrome oxidase C subunit III ( $\operatorname{cox} 3)$ gene as a sensitive and specific target for molecular detection of Babesia gibsoni infection in dogs. Exp. Parasitol., 206:1-8.

Bhattacharjee K. and Samrah, P. C. (2013) Prevalence of haemoparasites in pet, working and stray dogs of Assam and North-East India: A hospital based study. Vet. World., 6: 874-878.

Conrad, P., J. W. Thomford, I. Yamane, J. Whiting, L. Bosma, T. Uno, H. J. Holshuh and Shelly, S. (1991). Haemolytic anaemia caused by Babesia 
gibsoni infection in dogs. J. Am. Vet. Med. Assoc. 199: 601-605.

Das M. K., S. Baidya, A. Mahato, S. Pandit, J.D. Ghosh, S. Chaudhuri and Das, M. (2015). Incidence Of Canine Babesiosis In And Around Kolkata, West Bengal, India. Explor. Anim. Med., 5: 102-107.

El-Bahnasawy M.M., H.H.M. Khalil, T.A. Morsy (2011) Babesiosis in an Egyptian boy acquired from pet dog, and a general review. J. Egypt. Soc. Parasitol., 41:99108.

Jain K. J., B. Lakshmanan, S. Karunakaran, E. P. Jose and Aravindakshan, T. (2017). High prevalence of small Babesia species in canines of Kerala, South India. Vet. World, 11(10): 1319-1323.

Kalaivanan M., S. Saravanan and G. Ponnudurai (2018) Identification of Babesia gibsoni in dogs from Namakkal region by polymerase chain reaction. $\mathrm{J}$. Entomol. Zool. Stud., 6(5): 1146-1148.

Karunakaran S., U. N. Pillai and H. P. Sasidharan (2011). Babesia gibsoni infection in a German Shepherd dog. Vet. World, 4(6): 269-270.

Koster L.S., R. G. Lobetti and P. Kelly (2015). Canine babesiosis: a perspective on clinical complications, biomarkers, and treatment. Veterinary Medicine: Research and Reports, 6: 119-128.

Laha R., K. Bhattacharjee, P. C. Sarmah, M. Das, A. Goswami, D. Sarma and Sen, A. (2013). Babesia infection in naturally exposed pet dogs from a northeasternstate (Assam) of India: detection by microscopyand polymerase chain reaction. J Parasit Dis. 38(4): 389-393.

Mahalingaiah M. K. C., M. Asoor, R. P. Thimmaiah, H. D. Narayanaswamy, S. Y. Mukartal, A. M. Elattuvalappil, N. Chikkahonnaiah, S. Gupta and Singh, S. (2017). Prevalence of Canine Babesiosis in Different Breeds of Dogs in and Around Bengaluru. J. Anim. Vet. Adv., 5(3): 140-144.

Matijatko V., V, Mrljak, I. Kis, N. Kucer, J. Forsek, T. Zivicnjak, Z. Romic, Z. Simec and Ceron, J. J. (2007). Evidence of an acute phase response in dogs naturally infected with Babesiacanis. Vet. Parasitol., 144: 242-250.

Matsuu A., Y. Koshida, M. Kawaharaa, K. Inoue, H. Ikadai, Y. Hikasa, S. Okano and Higuchi, S. (2004). Efficacy of atovaquone against Babesiagibsoniin vivo and in vitro. Vet. Parasitol., 124: 9-18.

Miyama T., Y. Sakata, Y. Shimada, S. Ogino, M. Watanabe, K. Itamoto, M. Okuda, R. A. Verdida, X. Xuan, H.Nagasawa and Inokuma, H. (2005). Epidemiological Survey of Babesia gibsoni Infection in Dogs in Eastern Japan. J. Vet. Med. Sci., 67(5): 467-471.

Schnittger L., Rodriguez A. E. , FlorinChristensen M. and Morrison D. A. (2012). Babesia: A world emerging. Infection, Genetics and Evolution,12: 1788-1809.

Singh A., H. Singh, N. K. Singh, N. D. Singh and Rath, S. S. (2014). Canine Babesiosis in Northwestern India: Molecular Detection and Assessment of Risk Factors. Biomed Res. Int., 741785: 1-5.

Solano-Gallego L. and Baneth, G. (2011). Babesiosis in dogs and cats-Expanding parasitological and clinicalspectra. Vet. Parasitol., 181: 48- 60.

Yogeshpriya S., M. Sivakumar, M. Saravanan, M. Venkatesan, M. Veeraselvam, K. Jayalakshmi and Selvaraj, P. (2018). Clinical, haemato-biochemical and ultrasonographical studies on naturally occurring Babesia gibsoni infection in dogs. J. Entomol. Zool. Stud., 6(1): 13341337.

\section{How to cite this article:}

Shinde, S. S., B. N. Ambore, P. D. Pawar, S. B. Swami, G. D. Wankhede and Mote, C. S. 2021. Diagnosis of Babesia gibsoni in dogs by Molecular and Microscopy Techniques. Int.J.Curr.Microbiol.App.Sci. 10(02): 2285-2290. doi: https://doi.org/10.20546/ijcmas.2021.1002.272 